\title{
Desmoid tumours in familial adenomatous polyposis
}

\author{
A K Gurbuz, F M Giardiello, G M Petersen, A J Krush, G J A Offerhaus, S V Booker, \\ M C Kerr, S R Hamilton
}

\begin{abstract}
Desmoids are rare, benign fibromatous lesions, which can arise in patients with familial adenomatous polyposis (FAP), a disorder caused by germline adenomatous polyposis coli (APC) gene mutation. This study investigated the risk of desmoids in FAP, the relation between specific APC gene mutations and desmoid formation, and the clinical characteristics of FAP patients with desmoids. Eighty three of 825 FAP patients $(10 \%)$ from 49 of 161 kindreds $(30 \%)$ had desmoids. The absolute risk of desmoids in FAP patients was $2 \cdot 56 / 1000$ person years; comparative risk was 852 times the general population. APC gene mutations were similar in families with and without desmoids. The female/male ratio was $1.4(p=N S)$. Previous abdominal surgery was noted in $68 \%$ of patients with abdominal desmoids $(55 \%$ developed within five years postoperatively). Desmoid risk in FAP family members of a desmoid patient was $25 \%$ in first degree relatives $v 8 \%$ in third degree relatives. Desmoids are a comparatively common complication of FAP associated with surgical trauma and familial aggregation. Desmoid development was not linked to specific APC gene mutations and was not found predominantly in women. Studies of chemopreventive therapy, given within five years after abdominal surgery, should be considered in FAP patients with a family history of desmoid disease.
\end{abstract}

(Gut 1994; 35: 377-381)

Medicine, Pathology, and Oncology Center, The Johns Hopkins University School of Medicine and Department of

Epidemiology, The Johns Hopkins University School of Hygiene and Public Health, Baltimore, Maryland

F M Giardiello

GM Petersen

A J Krush

$S$ V Booker

M C Kerr

S R Hamilton

The Department of Pathology, Academic University Amsterdam, The Netherlands G J A Offerhaus

Division of

Gastroenterology

Gulhane Military

Medical Academy,

Ankara, Turkey

A K Gurbuz

Correspondence to:

Dr F M Giardiello, Division of Gastroenterology, Blalock 935, The Johns Hopkins Hospital, 600 North Wolfe Street, Baltimore, Maryland 21287, USA.

Accepted for publication 13 July 1993 FAP patients are estimated to be affected by desmoids, ${ }^{9-14}$ but a comprehensive risk analysis in FAP has not been reported.

The cause of desmoids is unclear. Surgical and physiological trauma have been implicated as precipitating factors. ${ }^{15}$ In FAP patients, desmoid development has been associated with abdominal surgery, ${ }^{16-18}$ pregnancy, ${ }^{11}{ }^{17} 19$ and exposure to oral contraceptives. ${ }^{1120}$ Also, family history of desmoids may be an important risk factor in the development of desmoids, but this predisposition remains controversial. ${ }^{1821}$ The possible relations of specific APC gene mutations to the development of desmoids has not been explored in detail.

The identification of risk factors for desmoids could have implications on strategies for prevention. Therefore, we used data from our large FAP registry to: (a) estimate the absolute and comparative risk of desmoid formation in FAP patients, (b) analyse the relation between specific codon mutations of the APC gene and desmoid formation, and (c) analyse the clinical characteristics of FAP patients with desmoids to evaluate the influence of sex, surgery, and family history of desmoid on desmoid formation.

\section{Methods and materials}

Data on the clinical characteristics and occurrence of desmoid disease were collected by retrospective review of medical records and questionnaire data in The Johns Hopkins Polyposis Registry, which contains 825 FAP patients from 161 pedigrees. The period of analysis was 1 January 1969 to 31 December 1990 . Eighty three FAP patients $(10 \%)$ had a clinically evident desmoid during this period. The presence of a desmoid was verified by histopathological review in 45 cases, by physician and surgical reports in 36 cases, and by patient report in two cases.

The risk of desmoid in FAP patients was calculated by person year analysis. For this risk analysis, patients with FAP were considered to be at risk for desmoid from birth until death. Observation time was from birth until date of last contact, date of death, date of diagnosis of desmoid, or closing date of the study.

The specific type and location of APC gene mutation was characterised in 28 unrelated FAP patients from the Polyposis Registry who were evaluated consecutively at The Johns Hopkins Hospital. The families of these 28 FAP patients included 13 with a member who had desmoid disease and 15 families without desmoids. APC gene mutation was reported previously. ${ }^{22}$ In brief, genomic DNA was prepared from peripheral blood leucocytes. The coding region of the APC gene was amplified by polymerase chain reaction (PCR) in 31 segments. The PCR products showing abnormalities in RNase protection analysis were cloned and then sequenced. Sequencing of both strands of genomic DNA was performed to confirm a mutation.

The effect of family history of desmoid on development of desmoid disease in FAP patients 
TABLE I Clinical characteristics of FAP patients with desmoids in The Johns Hopkins Polyposis Registry

\begin{tabular}{lc}
\hline No and prevalence of desmoid patients & $83 / 825(10 \%)$ \\
No and prevalence of desmoid kindreds & $49 / 161(30 \%)$ \\
Sites of desmoid tumours (\%) & $60(72)$ \\
Abdominal & $11(12)$ \\
Extra-abdominal & $3(5)$ \\
Abdominal and extra-abdominal & $9(11)$ \\
Site unknown & $31(15)(1-72)$ \\
Mean age of desmoid diagnosis, years (SD) (range) & \\
Timing of desmoid diagnosis (\%) & $11(13)$ \\
Before FAP diagnosis & $10(8)$ \\
Years before (SD) & $16(19)$ \\
Concurrent with FAP diagnosis & $56(68)$ \\
After FAP diagnosis & $9(9)$ \\
Years after (SD) & $47 / 36(1 \cdot 4)$ \\
Sex: female/male (ratio] &
\end{tabular}

$\mathrm{FAP}=$ familial adenomatous polyposis.

was evaluated in two ways. Firstly, the distribution of desmoid cases among FAP kindreds was characterised, and the risk of desmoid in families was calculated after adjusting for kindred size. Secondly, an application of the proband method to correct for ascertainment ${ }^{23}$ was used to determine the empiric risk of desmoid formation in first, second, and third degree relatives with FAP. This method was selected because of the high ascertainment probability of desmoid cases in this longterm polyposis registry. With this correction, a pedigree was replicated as many times as there were desmoid cases, and in each replicate a different proband (desmoid case) was designated. The empirical risk to first, second, and third degree relatives was thus differently enumerated in each replicate.

Where appropriate, continuous variables were analysed for statistical significance by two tailed $t$ tests. Discontinuous variables were compared by $\chi^{2}$ or Fisher's exact tests. Statistical significance was defined as $\mathrm{p}<0 \cdot 05$. Survival was assessed by lifetable analysis (True Epistat, Richardson, Texas).

Our findings were also compared with published reports obtained through MEDLINE and obtained by the BRS Colleague Search Service.

Frameshrift mutations

Point mutations

* Multiple desmoid members

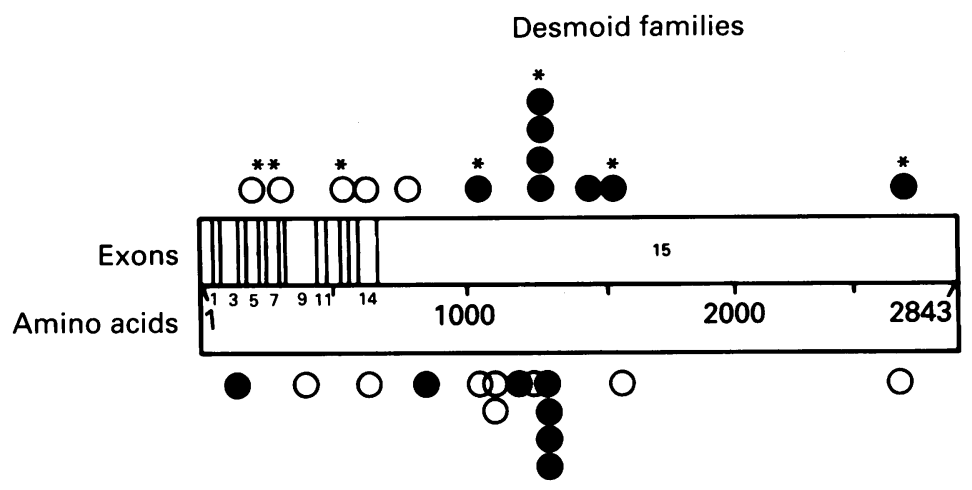

Non-desmoid families

Figure 1: Distribution of adenomatous polyposis coli mutations in familial adenomatous polyposis pedigrees with and without a member having desmoid disease. This diagram shows the position of the germline mutations in the proband of 13 pedigrees with desmoid members and 15 pedigrees without desmoid members comparative with the APC gene product and exon structure. Mutations occurring in families with multiple desmoid members are also shown by an asterisk. The boxes correspond to the exons $(1,3,5,7,11,14$, and 15 are numbered for reference) and the numbers below represent amino acid residues $(1,1000,2000$, and 2843). The location and type of APC gene mutations were similar in the families with and without desmoids and in the families with single and multiple members with desmoids.

\section{Results}

Eighty three of 825 FAP patients (10\%) from 49 of 161 kindreds (30\%) in The Johns Hopkins Registry had desmoids (Table I). From our person year analysis, the absolute risk of desmoid development in FAP patients was 2.56/ 1000 person years $(0 \cdot 00256 /$ person year $)$, which was 852 times the risk of the general population.

The location and type of APC gene mutation in the families with a member who had desmoid disease were compared with families who had no desmoids (Fig 1). In both desmoid and non-desmoid pedigrees, mutations occurred throughout the length of the APC gene, and the types of mutation (frameshift $v$ point mutation) were similar.

The sites of desmoids included 60 abdominal desmoids, 11 extra-abdominal, three both abdominal and extra-abdominal, and nine unspecified. Other extraintestinal manifestations of FAP (osteomas, epidermoid cysts, sebaceous cysts, pigmented ocular fundus lesions, or clinically occult osteosclerotic jaw lesions) were found in 49 of 83 (59\%) desmoid patients. The mean (SD) age of desmoid diagnosis in the study population was 31 (15) years (range 1-72). The occurrence of desmoids increased with age until the fifth decade of life (Fig 2). There was no difference by sex in mean age at diagnosis or age distribution of desmoids.

In 56 of 83 patients $(68 \%)$, the diagnosis of desmoid disease occurred after the diagnosis of FAP (mean of 9 (9) years after the diagnosis of FAP); in 11 patients (13\%), desmoids developed a mean of $10(8)$ years before the diagnosis of FAP; in $16(19 \%)$ patients both diagnoses were made concomitantly. In this cohort, the mean follow up time after desmoid diagnosis was 14 years (range 0.5-44). In five patients, desmoids occurred in the first three years of life. In all five cases, the desmoids were extra-abdominal in location, and three of these patients had multiple desmoids.

There was only a slight female predominance in this desmoid cohort with a female to male ratio of $1.4(p=N S)$. Thirty three of 47 women $(70 \%)$ developed desmoids in the childbearing period of 15-45 years of age. Similarly, 25 of 36 male patients $(69 \%)$ developed desmoids in the same age range. Twenty two of 33 female patients $(66 \%)$ of childbearing age had one or more children before desmoid diagnosis.

A previous history of abdominal surgery was present in 43 of $63(68 \%)$ patients with abdominal desmoids. Twenty two patients had prophylactic colectomy as the only abdominal operation before abdominal desmoid formation. In this subgroup, the mean (SD) age at time of colectomy was 29 (13) years, which was not statistically significantly different from the age of colectomy of $256 \mathrm{FAP}$ patients without desmoids ( 25 (9) years). In the 22 colectomy patients with desmoids, the onset of desmoids occurred a mean of 9 (10) years after surgery, but in most patients, desmoids occurred within the first five years postoperatively (12/22 patients; $55 \%)$. Also, the data suggest a relation between younger age at surgery and shorter time to desmoid diagnosis: desmoids occurred in the first five years postoperatively in 10 of 14 patients 


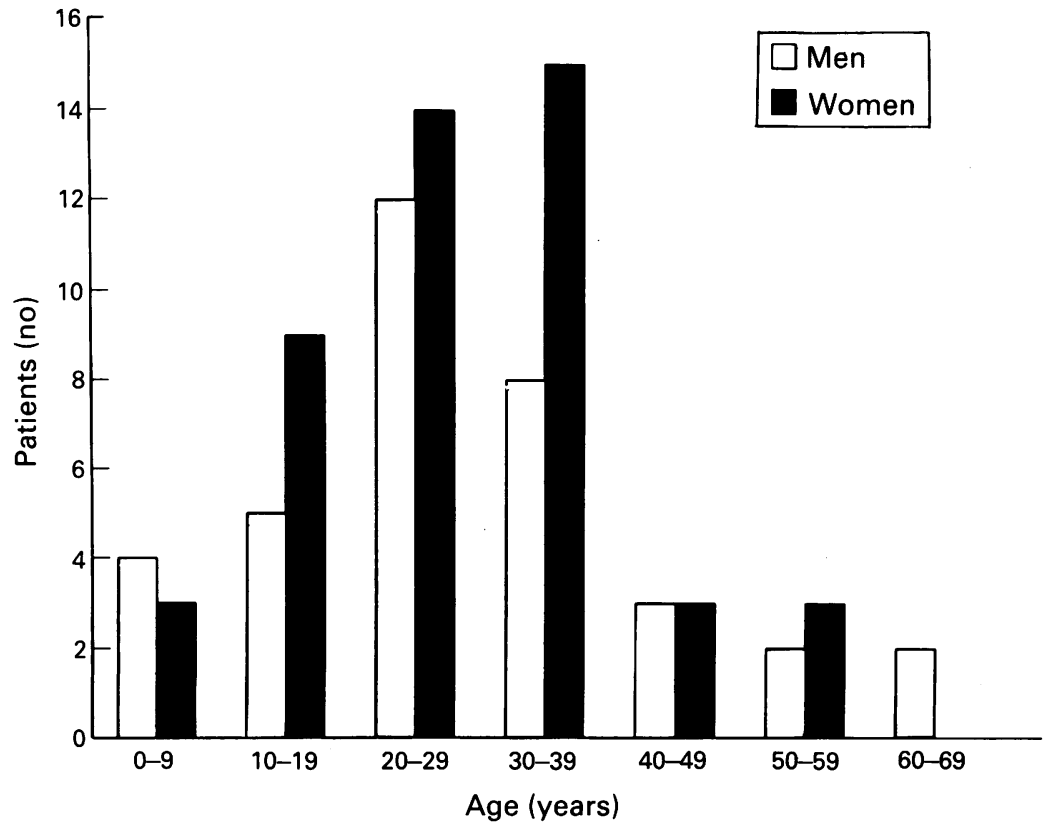

Figure 2: Age of diagnosis of desmoid tumours in men and women with familial adenomatous polyposis. The occurrence of desmoids increased with age until the fifth decade of life.

with a prophylactic colectomy before age 30 years compared with two of eight patients with a prophylactic colectomy after age 30 years $(\mathrm{p}=$ 0.048).

Forty nine of $83(59 \%)$ desmoid patients, representing 15 kindreds, had a family history of desmoids. Within kindreds, the percentage of FAP patients affected with desmoids ranged from $10 \%(1 / 10)$ to $87 \%(6 / 7)$ and $100 \%(2 / 2)$. The prevalence of desmoids in kindreds with at least one desmoid case was $83 / 389$, or $22 \%$ (Table II). When kindreds with more than one desmoid case were evaluated, the prevalence was similar $(49 / 216 ; 23 \%)$. When the risk by degree of relation to a desmoid case was examined, however, first degree relatives of a desmoid patient were at greater risk of desmoids than more distant relations. As shown in Table III, the empiric risk to first degree relatives was $25 \%$, which was more than twice that of second and third degree relatives. By contrast, the risk to second and third degree relatives approached the overall $10 \%$ risk of desmoids in FAP patients in general. As Figure 1 shows, the location and type of APC gene mutation did not differ among families with single or multiple members with desmoid disease.

Complications from desmoid were the cause of death in eight of 83 cohort patients (10\%). By lifetable analysis, the survival rate from desmoids was $93 \%$ at five years and $79 \%$ at 20

TABLE II Distribution of desmoid cases among FAP kindreds

\begin{tabular}{lll}
\hline $\begin{array}{l}\text { No of desmoid } \\
\text { cases/kindred }\end{array}$ & $\begin{array}{l}\text { Observed No of } \\
\text { kindreds }\end{array}$ & $\begin{array}{l}\text { Total No of } \\
\text { FAP cases }\end{array}$ \\
\hline 0 & 112 & 446 \\
1 & 34 & 163 \\
2 & 7 & 52 \\
3 & 3 & 52 \\
4 & 1 & 12 \\
5 & 2 & 65 \\
6 & 2 & 35 \\
Total & 161 & 825 \\
\hline
\end{tabular}

TABLE III Empiric risk to FAP relatives of having an FAP family member with desmoid disease

\begin{tabular}{lll}
\hline $\begin{array}{l}\text { Degree of relation to } \\
\text { desmoid case }\end{array}$ & $\begin{array}{l}\text { No of desmoid cases/ } \\
\text { No of FAP cases }\end{array}$ & $\begin{array}{l}\text { Risk of } \\
\text { desmoid }\end{array}$ \\
\hline First degree & $59 / 238$ & $25 \%$ \\
Second degree & $27 / 251$ & $11 \%$ \\
Third degree & $17 / 218$ & $8 \%$ \\
\hline
\end{tabular}

*Using application of Weinberg proband correction, in which a pedigree is replicated for each desmoid case.

years. The mean (SD) time from diagnosis of desmoid to death from desmoid was 6 (6) years, and the mean age of death in these patients was 40 years. Eighteen additional cohort patients $(22 \%)$ died from colorectal cancer a mean of 13 years after desmoid diagnosis.

\section{Discussion}

Patients with familial adenomatous polyposis are at risk for a wide variety of extracolonic manifestations including desmoids. By person year analysis, our cohort of FAP patients had an 852fold increased risk above the general population for the development of these tumours. The risk of desmoid development did not seem to be associated with a specific location or type of mutation of the APC gene. The location of the mutations seen in FAP pedigrees with desmoids spanned the APC gene. Also, there were no apparent differences in mutation location or type between pedigrees with and without desmoid members. The mutations seen in our 28 pedigrees are representative of the location and type of mutations in 88 other pedigrees reported in published works. ${ }^{+72+31}$ Thus, genetic testing for APC gene mutation will not identify a subset of FAP patients at higher risk for desmoid formation.

The occurrence of desmoid formation increased with age until the fifth decade of life. Interestingly, we found that all five patients with desmoids at very young age (under the age of 3 ) had extra-abdominal desmoids and three of these had multiple desmoids. This young subset of patients accounted for $45 \%$ of FAP patients with extra-abdominal desmoids and may represent a comparatively unique clinical group.

Desmoids occurred in $10 \%$ of our large registry of FAP patients, a frequency consistent with other reported series. ${ }^{911183233}$ Moreover, almost $10 \%$ of those with desmoids died from this complication at a young age (mean 40 years) comparatively shortly (mean six years) after diagnosis, although by lifetable analysis the survival at 20 years was $79 \%$. Colorectal cancer contributed substantially to death as 18 additional desmoid patients $(22 \%)$ died from colorectal cancer with a mean duration of 13 years after desmoid diagnosis.

The pathogenic factors in desmoid disease are not well understood. Desmoids have been reported to predominate in women with FAP on birth control pills, ${ }^{1120}$ and in female FAP patients of childbearing age ${ }^{17} 19$ most often after parturition (Table IV). Desmoids have been seen to enlarge during pregnancy. "These findings have been made in a small number of FAP patients, some of whom had previous abdominal surgery. 
TABLE IV Summary of desmoid tumour features in FAP

\begin{tabular}{lcllll}
\hline & $\begin{array}{l}\text { No of } \\
\text { FAP } \\
\text { patients }\end{array}$ & $\begin{array}{l}\text { No of } \\
\text { desmoid } \\
\text { patients }\end{array}$ & $\begin{array}{l}\text { Mean age } \\
\text { of desmoid } \\
\text { diagnosis }\end{array}$ & $\begin{array}{l}\text { Female/male } \\
\text { ratio }\end{array}$ & Reference \\
\hline Institution & 325 & $29(9 \%)$ & 30 & $3 \cdot 0$ & 11 \\
Cleveland Clinic & 496 & $40(8 \%)$ & 29 & $1 \cdot 8$ & 21 \\
$\begin{array}{l}\text { Memorial Sloan Kettering } \\
\begin{array}{l}\text { University Central Hospital } \\
\text { (Helsinki) }\end{array}\end{array}$ & 168 & $19(11 \%)$ & 29 & $1 \cdot 3$ & 32 \\
$\begin{array}{l}\text { University of Tokyo } \\
\text { The Johns Hopkins Hospital }\end{array}$ & 1050 & $71(7 \%)$ & 32 & $1 \cdot 8$ & 33 \\
& 825 & $83(10 \%)$ & 31 & $1 \cdot 4$ & $\begin{array}{c}\text { Current } \\
\text { study }\end{array}$ \\
\hline
\end{tabular}

In contrast, the effect of female sex was not evident in our FAP study population: there was only slight female predominance in our cohort $(1 \cdot 4: 1)$, and the same percentage of men and women developed desmoids in childbearing years. These findings are supported by McAdam et $a l^{18}$ who found female predominance in desmoid patients without FAP but not desmoid patients with FAP.

Some investigators have identified surgical trauma as a precipitating factor for desmoid formation in FAP patients. ${ }^{3121617}$ Our findings support this concept, as $68 \%$ of our patients with an abdominal desmoid had had abdominal surgery. In smaller published series, the mean time from colectomy to desmoid formation was 2.3 years. ${ }^{1132}$ In our cohort, most patients developed desmoids by five years postoperatively, but the mean time to desmoid formation was nine years. The difference in these temporal findings probably relates to the much longer follow up in our patient population (almost 14 years $v 4$ years)

A similar mean age of prophylactic colectomy in FAP patients with and without abdominal desmoids in our cohort suggests that age at colectomy is not an important factor in desmoid formation. There was a slight suggestion, however, from our data that patients having prophylactic colectomy at a younger age developed desmoids sooner than patients who were older at colectomy. This finding needs further investigation because of the implications for timing of prophylactic colectomy.

Finally, the significance of family history of desmoids as a risk factor for the development of desmoids in other pedigree members has been unclear, as only a few families had been studied. Fifty nine per cent of our study patients from 15 families, however, had a family history of desmoids, and this frequency agrees with a previous review of published works ${ }^{18}$ that reported $56 \%$. In our pedigrees, the percentage of FAP patients affected with desmoids was as high as $86 \%(6 / 7)$ and $100 \%(2 / 2)$. Familial risk of desmoids was also shown by empiric risk analysis and the Weinberg proband method. These analyses showed that family history of desmoids is important and that first degree relatives of desmoid patients have a greater risk of desmoids than more distant relatives. Interestingly, familial aggregation of desmoids did not seem to be related to the location or type of APC gene mutations. Consequently, other factors must play a part, such as additional genetic loci or shared environmental effects.

Regardless of the mechanism, FAP patients who are first degree relatives of an FAP patient with a desmoid are at nearly 2.5 times the risk of developing a desmoid as FAP patients in general. Recognition of this higher risk group may justify a change in clinical management. For example, clinical trials of drugs such as sulindac or tamoxifen given in the first few years after abdominal surgery should be considered in FAP patients with a family history of desmoids to attempt to prevent desmoid development postoperatively.

This study was supported in part by The Clayton Fund and The McAshan Fund. We are indebted to Drs Kenneth W Kinzler, Bert Vogelstein, and Yusuke Nakamura for their contributions. We thank Ms Linda M Welch for secretarial support.

1 Pack GT, Ehrlich HE. Neoplasms of the anterior abdominal wall with special consideration of desmoid tumors; experience with 391 cases and collective review of literature. Int Abstr Surg 1944; 79: 177-98.

2 Dahn I, Jonsson N, Lundh G. Desmoid tumors. A series of 33 cases. Acta Chir Scand 1963; 126: 305-14.

3 Reitamo JJ, Scheinin TM, Hayry P. The desmoid syndrome. New aspects in the case, pathogenesis and treatment of desmoid tumor. Am 7 Surg 1986; 151: 230-7.

4 Joslyn G, Carlson M, Thliveris A, Albertsen H, Gelbert L, Samowitz W, et al. Identification of deletion mutations and three new genes at the familial polyposis locus. Cell 1991; 66: 600-13.

5 Nishisho I, Nakamura Y, Miyoshi Y, Miki Y, Ando H, Horii $\mathrm{A}$, et al. Mutations of chromosome $5 \mathrm{q} 21$ genes in FAP and colorectal cancer patients. Science 1991; 253: 665-9.

6 Groden J, Thliveris A, Samowitz W, Carlson M, Gelbert L, Albertsen $\mathrm{H}$, et al. Identification and characterization of the familial adenomatous polyposis coli gene. Cell 1991; 66: 589-600.

7 Kinzler KW, Nilbert MC, Su LK, Vogelstein B, Bryan TM, Levy DB, et al. Identification of FAP locus genes from chromosome 5q21. Science 1991; 253: 661-5.

8 Boland CR, Itzkowitz SH, Kim YS. Colonic polyps and the gastrointestinal polyposis syndromes. In: Sleisenger $M H$, Fordtran JS, eds. Gastrointestinal disease; pathophysiology, diagnosis, and management. 4th Ed. Philadelphia: WB Saunders, 1989: 1500-7.

9 Bussey HJR. Extracolonic lesions associated with polyposis coli. Proc $R$ Soc Med 1972; 65: 294

10 Jones EL, Cornell WP. Gardner's syndrome; review of the literature and report on a family. Arch Surg 1966; 92: 287 300

11 Jones IT, Jagelman DG, Fazio VW, Lavery IC, Weakley FL, McGannon E. Desmoid tumors in familial polyposis coli. Ann Surg 1986; 204: 94-7.

12 Richards RC, Rogers SW, Gardner EJ. Spontaneous mesenteric fibrosis in Gardner's syndrome. Cancer 1981; 47: mesenter.601.

13 Smith WG. Desmoid tumors in familial multiple polyposis. Proc Staff Meet Mayo Clin 1959; 34: 31-8.

14 Waddell WR, Gerner RE. Indomethacin and ascorbate inhibited desmoid tumors. F Surg Oncol 1980; 15: 85-90.

15 Fee HJ, Elkins RC, Jones EL. Gardner's syndrome: unusua presentation of abdominal pain. Am $\mathcal{F}$ Surg 1972; 123 532-4.

16 Karakousis CP, Beriian RA, Lopez R, Rao U. Mesenteric fibromatosis in Gardner's syndrome. Arch Surg 1978; 113 998-1000.

17 Harvey JC, Quan SHQ, Fortner JG. Gardner's syndrome complicated by mesenteric desmoid tumors. Surgery 1979 85: 475-7.

18 McAdam WA, Goligher JC. The occurrence of desmoids in patients with familial polyposis coli. BrF Surg 1970; 57: 61831 .

19 Kinsbrunner B, Ritter S, Domingo J, Rosenthal CJ. Remission of rapidly growing desmoid tumors after tamoxifen sion of rapidly growing desmoid

20 Waddell WR. Treatment of intra-abdominal and abdominal wall desmoid tumors with drugs that affect the metabolism of cyclic 3',5'-adenosine monophosphate. Ann Surg 1975; 181: $299-302$.

21 Klemmer S, Pascoe L, DeCosse J. Occurrence of desmoids in familial adenomatous polyposis of the colon. $A m \mathcal{F} \mathrm{Med}$ Genet 1987; 28: 385-92.

22 Miyoshi Y, Ando H, Nagase H, Nishisho I, Horii A, Miki Y, et al. Germ-line mutations of the APC gene in 53 familia adenomatous polyposis patients. Proc Natl Acad Sci 1992; 89: 4452-6.

23 Weinberg W. Mathematische Grundlagen der Probandemethode. $Z$ Ind Abst Vererb-Lehre 1927; 48: 179-228.

24 Nagase H, Miyoshi Y, Horii A, Aoki T, Ogawa M, Utsunomiya J, et al. Correlation between the location of germ-line mutations in the APC gene and the number of germ-line mutations in the APC gene and the number of colorectal polyps in familial

25 Stella A, Lonoce A, Resta N, Gentile M, Susca F, Mareni C et al. Familial adenomatous polyposis - identification of a new frameshift mutation of the APC gene in an Italian family. Biochem Biophys Res Commun 1992; 184: 1357-63.

26 Cottrell S, Bicknell D, Kaklamanis L, Bodmer WF. Molecula analysis of APC mutations in familial adenomatous polyposis and sporadic colon carcinomas. Lancet 1992; 340: 626-9.

27 Fodde R, Vanderluijt R, Wijnen J, Tops C, Vanderklift H, 
Vanleeuwencornelisse I, et al. Eight novel inactivating germ line mutations at the APC gene identified by denaturing gradient gel electroph

28 Olschwang S, Laurent-Puig P, Thuille B, Thomas G. Germline mutations of adenomatous polyposis coli (APC) gene in a series of French propositi for familial adenomatous polyposis. Gastroenterology 1992; 102: A384.

29 Paul P, Letteboer T, Coppes M. SSCP detection of APC gene mutations in familial adenomatous polyposis. Am $\mathcal{F}$ Hum Genet 1992; 51: A67.

30 Nagase $\mathrm{H}$, Miyoshi $\mathrm{Y}$, Horii A, Aoki T, Petersen G, Vogelstein B, et al. Germ-line mutations of the APC gene in patients with familial adenomatous polyposis: screening of 150 unrelated patients. Human Mutation 1992; 1: 767-73. 31 Wallis Y, MacDonald F, Rindl PM, Hulten M, McKeown C, Morton DG, et al. Germline APC mutation familial adenomatous polyposis in an Indian family. Lancet 1992; 340: 1035.

32 Jarvinen HJ. Desmoid disease as a part of familial adenomatous polyposis coli. Acta Chir Scand 1987; 153: 379-83.

33 Iwama T, Mishima Y, Utsunomiya J. The impact of familial adenomatous polyposis on the tumorigenesis and mortality at several organ sites; its rational treatment. Ann Surg 1993; 217: $101-8$. 